\title{
PELATIHAN INSTALLASI DAN OPERASIONAL BLENDED LEARNING UNTUK ADMIN FAKULTAS
}

\author{
Zamzami $^{1}$, Yogi Yunefri ${ }^{2}$, Didik Siswanto ${ }^{3}$ \\ ${ }^{1}$ Jurusan Sistem Informasi, Fakultas Ilmu Komputer, Universitas Lancang Kuning \\ 2, 3 Jurusan Teknik Informatika, Fakultas Ilmu Komputer, Universitas Lancang Kuning \\ Jalan Yos Sudarso KM. 08 Rumbai, Pekanbaru-Riau, (0761) 53108 -53236 \\ e-mail : ${ }^{1}$ zamzami@unilak.ac.id, ${ }^{2}$ yogiyunefri@unilak.ac.id,2didik@unilak.ac.id
}

\begin{abstract}
ABSTRAK
Proses pembelajaran di Fakultas Ilmu Pendidikan dan Kejuruan (FKIP) dan Fakultas Ilmu Administrasi (FIA) dosen selama ini memberikan materi dengan menampilkan materi kuliah menggunakan infokus, serta juga dengan menuliskan materi kuliah dipapan tulis. Pelaksanaan kuis kepada mahasiswa dilakukan setelah beberapa kali pertemuan, mahasiswa dituntut untuk mengerjakan dan menyelesaikan soal kuis yang diberikan oleh dosen dan kemudian langsung dikumpulkan setelah waktu habis atau selesai. Untuk pemberian serta pengumpulan tugas, dosen memberikannya pada saat jam perkuliahan berlangsung dan ada juga dosen yang memberikan tugas diakhir jam perkuliahan setelah dosen menyampaikan materi perkuliahan, dan pengumpulannya dilakukan pada saat pertemuan didalam kelas atau pada jadwal kuliah dihari berikutnya berupa Hardcopy sehingga dosen harus menyediakan waktu tertentu untuk mengkoreksinya. Untuk menghadapi permasalahan yang dihadapi oleh Fakultas Ilmu Pendidikan (FKIP) dan Fakulutas Ilmu Administrasi (FIA) penulis menyarankan dengan penggunaan media pembelajaran berbasis elektronik yaitu Blended Learning.
\end{abstract}

Kata Kunci : Unilak, Blended Learning, Teamviewer, Learning, Installasi

\begin{abstract}
The Learning process at Faculty of Education and Vocational Education (FKIP)) and the Faculty of Administrative Sciences (FIA) lecturers has been providing materials by displaying lecture materials using projector, as well as writing lecture materials on the blackboard. The student quiz is conducted after several meetings, the students are required to work on and complete the quiz given by the lecturer and then immediately collected after the time is up or finished. To give and collect the task, the lecturer give it during the lecture period and there are also lecturers who give the task at the end of the lecture after the lecturer delivered the lecture material, and the collection is done during the meeting in the class or on the next day schedule in the form of hardcopy so that the lecturer must certain to correct it. To face the problems faced by the Faculty of Education (FKIP) and Faculty of Administrative Sciences (FIA) the authors suggest with the use of electronic-based learning media that is Blended Learning.
\end{abstract}

Key words: Unilak, Blended Learning, Teamviewer, Learning, Installation 


\section{PENDAHULUAN}

Universitas Lancang Kuning, yang disingkat UNILAK berdiri dibawah naungan Yayasan Raja Ali Haji. UNILAK didirikan melalui Surat Keputusan Yayasan Raja Ali Haji No. 001/KEP-Yasrah/ 82 tanggal 9 Juni 1982. UNILAK sekarang ini memiliki 9 fakultas dengan 19 prodi strata-1 dan 2 prodi strata-2.

Proses pembelajaran di Fakultas Ilmu Pendidikan dan Kejuruan (FKIP) dan Fakultas Ilmu Administrasi (FIA) dosen selama ini memberikan materi dengan menampilkan materi kuliah kuliah menggunakan infokus, serta juga dengan menuliskan materi kuliah dipapan tulis. Pada saat dikelas dosen memberikan materi kuliah yang bersumber dari buku cetak dan mahasiswa menulisnya agar bisa dibaca dan dipelajari lagi ketika mahasiswa berada dirumah atau berada diluar lingkungan kampus.

Pelaksanaan kuis kepada mahasiswa dilakukan setelah beberapa kali pertemuan, mahasiswa dituntut untuk mengerjakan dan menyelesaikan soal kuis yang diberikan oleh dosen dan kemudian langsung dikumpulkan setelah waktu habis atau selesai.

Pimpinan yang bertindak sebagai atasan untuk melakukan pengawasan terhadap proses pembelajaran saat ini masih dilakukan dengan cara sidak langsung ke ruangan belajar sebatas pengecekan, hal ini menyebabkan tidak efektifnya cara yang dilakukan karena bisa saja mengganggu jadwal mengajar dosen yang bersangkutan.

Namun terdapat kendala di Fakultas Ilmu Pendidikan (FKIP) dan Fakultas Ilmu Administrasi (FIA) pada saat mahasiswa ingin mendapatkan bahan materi sebelum perkuliahan dimulai dikarenakan keterbatasan waktu yang dimiliki oleh dosen. Untuk pemberian serta pengumpulan tugas, dosen memberikannya pada saat jam perkuliahan berlangsung dan ada juga dosen yang memberikan tugas diakhir jam perkuliahan setelah dosen menyampaikan materi perkuliahan, dan pengumpulannya dilakukan pada saat pertemuan didalam kelas atau pada jadwal kuliah dihari berikutnya berupa Hardcopy sehingga dosen harus menyediakan waktu tertentu untuk mengkoreksinya. Orang tua mahasiswa saat ini tidak dapat mengetahui nilai dari anaknya, yaitu nilai tugas dan kuis anaknya selama perkuliahan.

\section{BAHAN DAN METODE}

Pelaksanaan kegiatan $\mathrm{I}_{\mathrm{B}} \mathrm{M}$ ini dilakukan di Fakultas Ilmu Komputer dengan metode ceramah, praktikum, tanya jawab dan evaluasi pencapaian target melalui kuisioner. Pelatihan dilakukan selama satu hari dimana peserta akan mendapatkan 1(satu) Compact Disk yang berisi aplikasi Moodle dan modul.

Metode ceramah diberikan saat pemberian materi dengan menggunakan slide persentasi, handout materi dan flashdisk booting. Metode evaluasi pencapaian target dilakukan pada awal (pre test) dan akhir kegiatan (post test). Hal ini untuk mengetahui tingkat pemahaman peserta dan menerima masukan untuk perbaikan pada kegiatan-kegiatan berikutnya. Secara rinci kegiatan pengabdian yang akan dilakukan sebagai berikut :

1. Kegiatan Sosialisasi penginstallan Aplikasi Teamviwer yang berfungsi sebagai aplikasi yang memungkikan satu komputer dengan komputer lainnya berkomunikasi walaupun dengan jarak yang jauh asalkan terkoneksi internet pada kedua komputer, serta juga memungkian kedua komputer saling berbagi file, chatting serta melakukan video call, kegiatan ini terbagi menjadi : 


\section{a. Pengenalan Teamviewer \\ b. Setting Teamviewer}

2. Installasi Moodle, yang terdiri dari kegiatan :

a. Pengenalan aplikasi Moodle.

b. Pengisian Content Blended Learning

Sebelum melakukan installasi sotware Xampp dan aplikasi Moodle, sebaiknya mempersiapkan bahan-bahan yang berkaitan dengan installasi seperti laptop, CD, dan Software Xampp dan aplikasi Moodle.

\section{HASIL DAN PEMBAHASAN}

Pelaksanaan kegiatan pengabdian ini dilaksanakan pada 3 April - 4 April 2018 dari jam 08.30 - 12.00 WIB, bertempat di Laboratorium Pangkalan Data Perguruan Tinggi (PDPT) Universitas Lancang Kuning Rumbau, Pekanbaru-Riau. Pelatihan ini dihadiri oleh 13 orang peserta, 8 peserta dari Fakultas Kejuruan dan Ilmu Pendidikan (FKIP) dan 5 peserta dari Fakultas Ilmu Administrasi (FIA).

Pengabdian yang dilakukan dibagi dalam 2(dua) tahap, pada tahapan pertama peserta pelatihan diberikan pelatihan menginstalasi aplikasi Teamviewer, serta mensetting aplikasi tersebut supaya bisa terkoneksi ke komputer pemakalah. Selanjutnya pada tahap kedua peserta pelatihan diberikan penjelasan tentang apa itu aplikasi moodle dan selanjutnya peserta pelatihan oleh admin moodle dijadikan sebagai admin pengisi konten matakuliah, dimana pada askhirnya admin pengisi konten matakuliah manambahkan matakuliah sesuai dengan yang mereka ampu.

Berikut ini akan dipaparkan mengenai hasil yang telah dicapai oleh peserta pelatihan pertiap tahapannya :

1. Tahap Pertama

Pada tahap ini peneliti memberikan penjelasan kepada peserta pelatihan tentang aplikasi Teamviewer, apa fungsi dan manfaatnya serta pelatihan installasi aplikasi tersebut ke computer masing-masing peserta pelatihan. Setelah installasi peserta pelatihan diajarkan cara setting supaya peserta pelatihan bisa mengkoneksikan komputer mereka ke komputer pemateri.

Pada tahap ini setelah selesai pemaparan materi dan pelatihan installasi dan setting, semua komputer peserta pelatihan akhirnya terkoneksi kekomputer pemateri.

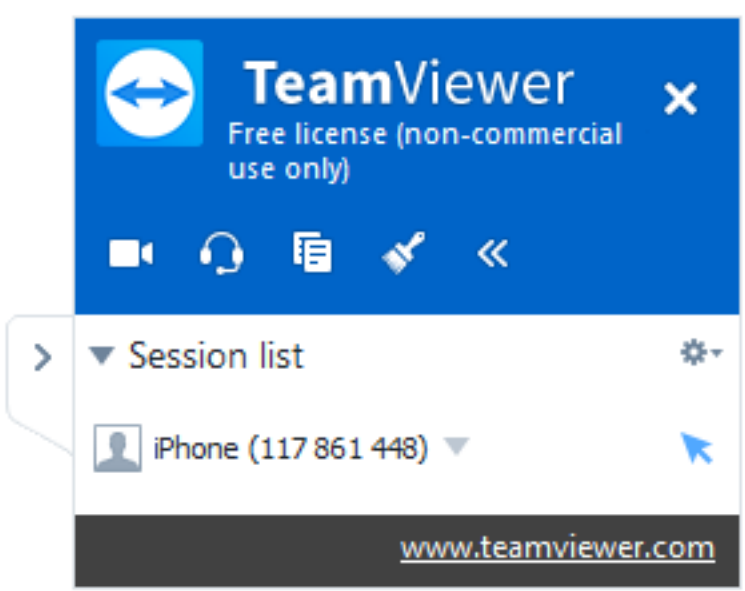




\section{Tahap Kedua}

Gambar 1. Tampilan Teamviewer

Pada tahap kedua ini dilanjutkan dengan pemberian materi tentang aplikasi moodle yang biasanya digunakan sebagai alat bantu alternatif pembelajaran. Setelah materi secara teori diberikan selanjutnya peserta pelatihan yang terdiri dari ketua jurusan dan sekretaris jurusan diangkat sebagai admin pengisi konten matakuliah. Pengangkatan admin pengisi konten matakuliah ini bertujuan agar nantinya setiap dosen yang ada difakultas tidak perlu lagi menghubungi super admin untuk ditambahkan matakuliahnya. Jadi setelah dijadikan admin pengisi konten matakuliah masing-masing admin mengisikan matakuliah yang mereka ampu dan akhirnya mengisi konten setiap pertemuan dengan materi, RPS, tugas dan kuiz.

Dari hasil pelatihan yang telah diadakan, rincin peserta yang hadir dapat dilihat pada tabel dibawah ini :

Tabel 2. Daftar hadir peserta pelatihan

\begin{tabular}{|c|l|c|}
\hline No. & \multicolumn{1}{|c|}{ Nama Peserta } & Fakultas \\
\hline 1. & Pebriana Marlinda & FIA \\
\hline 2. & Eka & FIA \\
\hline 3. & Syahdan & FKIP \\
\hline 4. & Dwi Herlinda & FIA \\
\hline 5. & Bunga Chintia Utami & FIA \\
\hline 6. & Alexsander Yandra & FIA \\
\hline 7. & Sri Wahyuni & FKIP \\
\hline 8. & Suharni & FKIP \\
\hline 9. & Herdi & FKIP \\
\hline 10. & Arlian Firda & FKIP \\
\hline 11. & R. Ramadansur & FKIP \\
\hline 12. & Kurniawan & FKIP \\
\hline 13. & Dahler & \\
\hline
\end{tabular}

Tingkat keberhasil dari pelatihan installasi dan operasional Blended Learning ini diukur menggunakan kuisioner pre test dan post test yang diberikan kepada peserta pelatihan. Hasil perhitungan kuisioner ini nantinya akan ditampilkan ke grafik.

Pada pelatihan ini pre test dan post test diberikan pertanyaan sebanya 10 pertanyaan. Skor untuk setiap jawaban adalah :

$1=$ Sangat Tidak Mengerti (STM)

$2=$ Tidak Mengerti $(\mathrm{TM})$

$3=$ Kurang Mengeti $(\mathrm{KM})$

$4=$ Mengerti $(\mathrm{M})$

$5=$ Sangat Mengerti $(\mathrm{SM})$

Jumlah responde 13 orang sehingga didapat hasil skor dari pre test untuk pertanyaan yang diajukan kepada responden adalah sebagai berikut : 
Tabel 3. Hasil Skor Pre Test

\begin{tabular}{|c|l|c|c|c|c|c|c|c|c|c|c|}
\hline No. & \multicolumn{1}{|c|}{ Nama Peserta } & P1 & P2 & P3 & P4 & P5 & P6 & P7 & P8 & P9 & P10 \\
\hline 1. & Pebriana Marlinda & 1 & 1 & 1 & 1 & 1 & 2 & 1 & 1 & 1 & 1 \\
\hline 2. & Eka & 1 & 1 & 1 & 1 & 1 & 1 & 1 & 1 & 1 & 1 \\
\hline 3. & Syahdan & 1 & 1 & 1 & 1 & 2 & 3 & 1 & 1 & 1 & 1 \\
\hline 4. & Dwi Herlinda & 1 & 1 & 1 & 1 & 1 & 1 & 1 & 1 & 1 & 1 \\
\hline 5. & Bunga Chintia Utami & 1 & 1 & 1 & 1 & 1 & 1 & 1 & 1 & 1 & 1 \\
\hline 6. & Alexsander Yandra & 1 & 1 & 1 & 1 & 1 & 1 & 1 & 1 & 1 & 1 \\
\hline 7. & Sri Wahyuni & 1 & 1 & 1 & 1 & 3 & 3 & 1 & 1 & 1 & 1 \\
\hline 8. & Suharni & 1 & 1 & 1 & 1 & 3 & 3 & 1 & 1 & 1 & 1 \\
\hline 9. & Herdi & 1 & 1 & 1 & 1 & 3 & 3 & 1 & 1 & 1 & 1 \\
\hline 10. & Arlian Firda & 1 & 1 & 1 & 1 & 3 & 3 & 1 & 1 & 1 & 1 \\
\hline 11. & R. Ramadansur & 1 & 1 & 1 & 1 & 3 & 3 & 1 & 1 & 1 & 1 \\
\hline 12. & Kurniawan & 1 & 1 & 1 & 1 & 2 & 3 & 1 & 1 & 1 & 1 \\
\hline 13. & Dahler & 1 & 1 & 1 & 1 & 2 & 3 & 1 & 1 & 1 & 1 \\
\hline
\end{tabular}

Setelah pelaksanaan pelatihan kemudian diadakan post test yang berupa pemberian soal yang sama kembali kepada peserta pelatihan, sehingga di dapat hasil sebagai berikut :

Tabel 4. Hasil Skor Post Test

\begin{tabular}{|c|l|c|c|c|c|c|c|c|c|c|c|}
\hline No. & \multicolumn{1}{|c|}{ Nama Peserta } & P1 & P2 & P3 & P4 & P5 & P6 & P7 & P8 & P9 & P10 \\
\hline 1. & Pebriana Marlinda & $\mathbf{5}$ & $\mathbf{5}$ & $\mathbf{5}$ & $\mathbf{5}$ & $\mathbf{5}$ & $\mathbf{5}$ & $\mathbf{4}$ & $\mathbf{5}$ & $\mathbf{5}$ & $\mathbf{4}$ \\
\hline 2. & Eka & $\mathbf{5}$ & $\mathbf{4}$ & $\mathbf{4}$ & $\mathbf{4}$ & $\mathbf{5}$ & $\mathbf{5}$ & $\mathbf{4}$ & $\mathbf{4}$ & $\mathbf{4}$ & $\mathbf{4}$ \\
\hline 3. & Syahdan & $\mathbf{5}$ & $\mathbf{5}$ & $\mathbf{4}$ & $\mathbf{5}$ & $\mathbf{5}$ & $\mathbf{5}$ & $\mathbf{5}$ & $\mathbf{4}$ & $\mathbf{5}$ & $\mathbf{4}$ \\
\hline 4. & Dwi Herlinda & $\mathbf{5}$ & $\mathbf{5}$ & $\mathbf{4}$ & $\mathbf{5}$ & $\mathbf{5}$ & $\mathbf{5}$ & $\mathbf{4}$ & $\mathbf{5}$ & $\mathbf{5}$ & $\mathbf{4}$ \\
\hline 5. & Bunga Chintia Utami & $\mathbf{5}$ & $\mathbf{5}$ & $\mathbf{4}$ & $\mathbf{5}$ & $\mathbf{5}$ & $\mathbf{5}$ & $\mathbf{4}$ & $\mathbf{5}$ & $\mathbf{4}$ & $\mathbf{4}$ \\
\hline 6. & Alexsander Yandra & $\mathbf{5}$ & $\mathbf{4}$ & $\mathbf{5}$ & $\mathbf{5}$ & $\mathbf{4}$ & $\mathbf{5}$ & $\mathbf{4}$ & $\mathbf{4}$ & $\mathbf{4}$ & $\mathbf{4}$ \\
\hline 7. & Sri Wahyuni & $\mathbf{5}$ & $\mathbf{4}$ & $\mathbf{5}$ & $\mathbf{5}$ & $\mathbf{5}$ & $\mathbf{5}$ & $\mathbf{5}$ & $\mathbf{5}$ & $\mathbf{5}$ & $\mathbf{4}$ \\
\hline 8. & Suharni & $\mathbf{5}$ & $\mathbf{5}$ & $\mathbf{5}$ & $\mathbf{5}$ & $\mathbf{4}$ & $\mathbf{5}$ & $\mathbf{5}$ & $\mathbf{4}$ & $\mathbf{5}$ & $\mathbf{4}$ \\
\hline 9. & Herdi & $\mathbf{5}$ & $\mathbf{5}$ & $\mathbf{4}$ & $\mathbf{5}$ & $\mathbf{5}$ & $\mathbf{5}$ & $\mathbf{5}$ & $\mathbf{5}$ & $\mathbf{5}$ & $\mathbf{5}$ \\
\hline 10. & Arlian Firda & $\mathbf{5}$ & $\mathbf{5}$ & $\mathbf{5}$ & $\mathbf{5}$ & $\mathbf{5}$ & $\mathbf{5}$ & $\mathbf{5}$ & $\mathbf{5}$ & $\mathbf{5}$ & $\mathbf{5}$ \\
\hline 11. & R. Ramadansur & $\mathbf{5}$ & $\mathbf{5}$ & $\mathbf{4}$ & $\mathbf{5}$ & $\mathbf{5}$ & $\mathbf{5}$ & $\mathbf{4}$ & $\mathbf{4}$ & $\mathbf{4}$ & $\mathbf{4}$ \\
\hline 12. & Kurniawan & $\mathbf{5}$ & $\mathbf{5}$ & $\mathbf{4}$ & $\mathbf{5}$ & $\mathbf{5}$ & $\mathbf{5}$ & $\mathbf{5}$ & $\mathbf{5}$ & $\mathbf{4}$ & $\mathbf{4}$ \\
\hline 13. & Dahler & $\mathbf{5}$ & $\mathbf{5}$ & $\mathbf{4}$ & $\mathbf{5}$ & $\mathbf{5}$ & $\mathbf{5}$ & $\mathbf{4}$ & $\mathbf{4}$ & $\mathbf{4}$ & $\mathbf{4}$ \\
\hline
\end{tabular}

Hasil dari pelatihan yang dilaksanakan berupa tampilan matakuliah dan conten isia dari matakuliah. Sebagai berikut : 


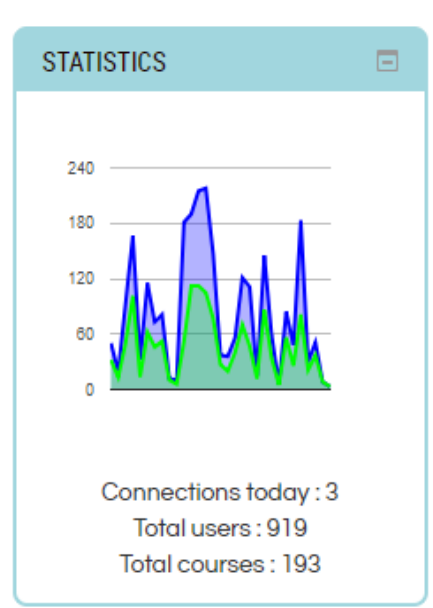

$\triangleright$ Sastra Indonesıa

\section{- Fakultas Kehutanan}

$\triangleright$ Kehutanan

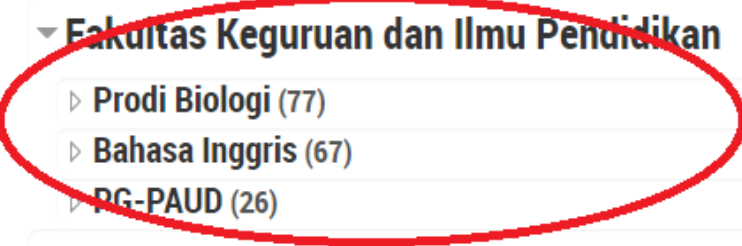

- Pasca Sarjana

$\triangleright$ Magister Manajemen

Magister Hukum

Gambar 2. Jumlah MTK yang sudah dibuat Fak. FIP

Dari gambar diatas dapat dilihat semua matakuliah yang ada di Fakultas FKIP sudah dimasukan kedalam blended learning. Selanjutnya setelah matakuliah diinputkan maka akan diisikan konten dari matakuliah tersebut, seperti terlihat pada gambar dibawah ini :

\section{Introduction to Translation}

Dosen: syahdan -

Dosen: syahdant syahdant

Gambar 3. Tampilan Matakuliah atas dosen Syahdan

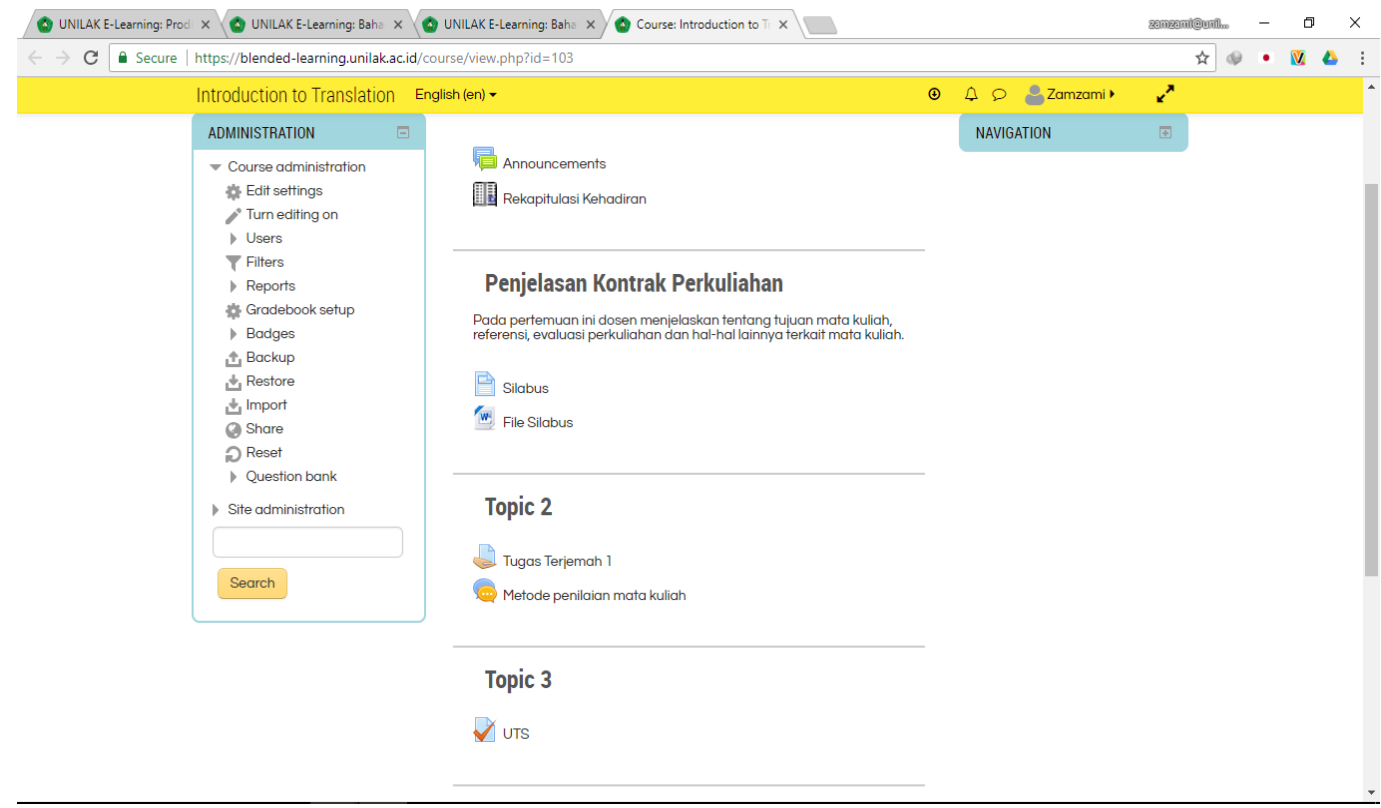

Gambar 4. Tampilan Konten Matakuliah atas dosen Syahdan 


\section{KESIMPULAN}

Berdasarkan hasil penjelasan dari kuisioner pre test dan post test yang sudah diadakan (seperti grafik di bab sebelumnya), maka penulis dapat mengambil beberapa kesimpulan :

a) Pengetahuan peserta pelatihan tentang aplikasi dan penggunaan Teamviewer secara keseluruhan mengalami peningkatan.

b) Dalam penggunaan aplikasi moodle yang merupakan aplikasi yang digunakan untuk blended secara grafik dilihat juga mengalami peningkatan, akan tetapi ada di pertanyaan ke 10, kemampuan hanya 2 orang atau sekitar 15\% yang sampai ke tingkat sangat mengerti.

\section{Daftar Pustaka}

[1] Barokati, Nisaul, and Fajar Annas. "Pengembangan Pembelajaran Berbasis Blended Learning pada Mata Kuliah Pemrograman Komputer (Studi Kasus: UNISDA Lamongan)." SISFO Vol 4 No 54 (2013).

[2] Syarif, Izuddin. "Pengaruh model blended learning terhadap motivasi dan prestasi belajar siswa SMK." Jurnal pendidikan vokasi 2.2 (2012).

[3] Kusairi, S. "Pengaruh Blended Learning terhadap Penguasaan Konsep dan Penalaran Fisika Peserta Didik Kelas X." Jurnal Pendidikan Fisika Indonesia 9.1 (2013).

[4] Azis, Yunia Mulyani. "The effectiveness of blended learning, prior knowledge to the understanding concept in economics." Educational Research International 2.2 (2013): 106-116.

[5] Prayitno, Wendhie, and L. P. M. P. Widyaiswara. "Implementasi Blended Learning Dalam Pembelajaran Pada Pendidikan Dasar dan Menengah." (2013). 